\title{
GAMBARAN PERILAKU RAMAH LINGKUNGAN MAHASISWA BINUS DITINJAU DARI TINGKAT KESADARAN LINGKUNGAN
}

\author{
Murty Magda Pane \\ Character Building Development Center, BINUS University \\ Jln. Kemanggisan Ilir III, No. 45, Kemanggisan - Palmerah, Jakarta Barat 11480 \\ murty.pane@gmail.com
}

\begin{abstract}
Environmental quality of Jakarta has further experienced decline. It is time for the society of Jakarta has higher environmental awareness, reflected from the frequent of friendly environmental behavior implemented. To intervene so that people behave environmentally friendly is certainly not easy, but the intervention can begin by getting an overview for environmental behavior of the society. This intervention can be initiated from public intellectuals. Binus students, as young intellectuals considering as one of the largest population in Jakarta, have great potentials in initiating interventions that lead to the formation of urban ecofriendly behavior to determine Jakarta. As the appropriate intervention, it requires initial overview of environmental behavior of Binus students. Hence this study took students in second semester as respondents. The objective of this study is to get the illustration of the level of environmental awareness of the students. Afterwards it is expected to be the basis for further research to determine appropriate interventions. This study used quantitative method to determine the level of environmental awareness of the respondent. While the results showed that the respondents' level of environmental awareness is still below the expectancy level.
\end{abstract}

Keywords: college students, environmental awareness level, environmental behavior

\begin{abstract}
ABSTRAK
Kualitas lingkungan kota Jakarta sudah mengalami kemerosotan yang jauh. Sudah saatnya masyarakat kota Jakarta memiliki kesadaran lingkungan yang tinggi yang tercermin dari frekuensi perilaku ramah lingkungan dilaksanakan. Melakukan intervensi agar masyarakat berperilaku ramah lingkungan tentunya tidak mudah, namun intervensi ini dapat dimulai dengan mendapatkan gambaran perilaku ramah lingkungan masyarakatnya. Intervensi ini dapat dimulai dari kalangan intelektual suatu masyarakat. Mahasiswa Binus, sebagai kalangan intelektual muda yang termasuk terbesar populasinya di Jakarta, berpotensi besar dalam memulai intervensi yang mengarah pada pembentukan perilaku ramah lingkungan masyarakat kota Jakarta. Untuk menentukan intervensi yang tepat diperlukan gambaran awal perilaku ramah lingkungan dari mahasiswa Binus, yang dalam penelitian ini diambil mahasiswa semester 2 sebagai responden. Sudah cukup tinggikah tingkat kesadaran lingkungan sehingga penelitian ini dapat menjadi dasar untuk penelitian selanjutnya untuk menentukan intervensi yang tepat. Penelitian ini menggunakan metode kuantitatif untuk mengetahui tingkat kesadaran lingkungan responden. Sedangkan hasil penelitian menunjukkan bahwa tingkat kesadaran lingkungan responden masih di bawah tingkat ekspektasi.
\end{abstract}

Kata kunci: mahasiswa, tingkat kesadaran lingkungan, perilaku ramah lingkungan 


\section{PENDAHULUAN}

Belum hilang dari ingatan bencana banjir yang melanda ibukota Jakarta pada 17 Januari 2013 silam. Bencana ini seakan telah menjadi momok bagi penduduk Jakarta tiap 5 tahun. Menurut perkiraan Gubernur DKI Jakarta, kerugian yang ditimbulkan saat itu mencapai Rp20 triliun. Kerugian yang terukur secara finansial ini belum termasuk korban jiwa yang mencapai angka 20 jiwa, juga jumlah orang yang terpaksa mengungsi sempat mencapai angka 50.000 jiwa (detikNews, 2013). Menilik kembali ke masa lalu, Jakarta memiliki sejarah mengalami bencana banjir pada tahun-tahun sebelumnya, yang cukup signifikan adalah pada tahun 1996, 2000, 2002, 2007, dan terakhir tahun 2013. Menurut WALHI dalam maiwanews.com, kerugian yang ditimbulkan akibat banjir pada 1996 mencapai angka Rp174 milyar dan pada 2000 mencapai angka Rp800 milyar. Sedangkan kerugian yang ditimbulkan oleh bencana banjir pada tahun 2002 dan 2007 dapat dilihat dalam tabel berikut.

Tabel 1 Perbandingan Bencana Banjir Jabodetabek Tahun 2002 dan 2007

\begin{tabular}{|c|c|c|}
\hline Deskripsi & Tahun $2002^{x}$ & Tahun $2007^{1 *}$ \\
\hline Curah Hujan & $\begin{array}{l}361,7 \mathrm{~mm} \\
\text { (rata-rata DKI Jakarta selama } 10 \\
\text { hari) }\end{array}$ & $\begin{array}{l}327 \mathrm{~mm} \\
\text { (rata-rata Jabodetabek } \\
\text { selama } 6 \text { hari) }\end{array}$ \\
\hline Luas genangan & $\begin{array}{l}331 \text { km2 di Jakarta } \\
100 \text { km2 di Bodetabek }\end{array}$ & $\begin{array}{l}454,8 \mathrm{~km} 2 \text { di Jakarta } \\
221 \mathrm{~km} 2 \text { di Tangerang dan } \\
\text { sekitarnya } \\
250 \mathrm{~km} 2 \text { total Depok, Bogor } \\
\text { dan Bekasi }\end{array}$ \\
\hline Korban Jiwa & 80 orang & 79 orang (status 12 Feb 07 ) \\
\hline Jumlah pengungsi & 381 orang & 590.407 (status 6 Feb 07) \\
\hline $\begin{array}{l}\text { Dampak } \\
\text { kerusakan }^{\ldots \times}\end{array}$ & $\begin{array}{l}\text { Langsung: Rp. } 5,4 \mathrm{~T} \\
\text { Ekonomi: Rp. 4,5 T }\end{array}$ & $\begin{array}{l}\text { Langsung: Rp. } 5,2 \mathrm{~T} \\
\text { Ekonomi (dampak tidak } \\
\text { langsung): Rp. } 3,6 \mathrm{~T}\end{array}$ \\
\hline 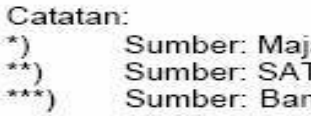 & $\begin{array}{l}\text { Tempo, } 18 \text { Februari } 2007 \\
\text { RLAK PBP DKI Jakarta dan media } \\
\text { unia } 2002 \text { (untuk tahun 2002) dan }\end{array}$ & $\begin{array}{l}\text { Februari } 2007 \\
\text { Analisis Bappenas (untul }\end{array}$ \\
\hline
\end{tabular}

(Sumber: Bappenas, 2007)

Penyebab banjir yang menyebabkan kerugian yang sangat besar ini disebabkan oleh beraneka ragam faktor, yaitu: curah hujan yang tinggi sejak Desember 2012, sistem drainase yang buruk, jebolnya beberapa tanggul di Jakarta, dan meningkatnya volume 13 sungai yang melintasi Jakarta. Curah hujan yang tinggi hingga 250-300 mm (melebihi kondisi banjir Jakarta tahun 2002 namun masih di bawah kondisi banjir Jakarta 2007 yang mencapai $340 \mathrm{~mm}$ ) tersebut ternyata membahayakan kondisi kota Jakarta dengan sistem drainase yang kemampuannya jauh di bawah angka tersebut untuk kapasitas penampungan. Ternyata desain drainase yang masih di bawah kapasitas curah hujan yang terjadi akhir-akhir ini dibantah oleh Menteri Djoko Kirmanto, yang menyatakan bahwa sampahlah yang menyebabkan penyumbatan drainase dan aliran air yang menuju pompa yang ada (Wikipedia, 2013).

Faktor-faktor lain penyebab banjir besar yang melanda Jakarta Januari 2013 lalu adalah: level tanah Jakarta yang sudah mencapai titik jenuh oleh hujan lebat 2-3 jam yang sering turun sejak awal bulan; luapan air dari beberapa sungai karena penyempitan dan pendangkalan; fungsi sungai yang sudah mandul tersebut diperparah dengan kondisi hulu sungai yang sudah rusak; dan hilangnya fungsi resapan di daerah puncak (hingga 50\% dibandingkan dengan 15 tahun yang lalu) akibat laju pembangunan yang tak terkendali. Selain ketiga faktor tersebut, juga ada beberapa faktor lain, misalnya penurunan permukaan tanah akibat eksploitasi air tanah yang berlebihan, tinggi permukaan air laut yang meningkat akibat pasang, atau ruang terbuka hijau yang luasnya tidak memenuhi syarat, yaitu 30\% luas wilayah, tetapi hanya 10\% dari luas wilayah (Tempo, 2013). 
Ancaman bencana ini tentunya membuat resah sebagian besar penduduk Jakarta. Walaupun ada pula sebagian penduduk Jakarta yang tidak mengalami musibah banjir, baik di daerah tempat tinggalnya maupun tempatnya beraktivitas, banjir membuat lalu lintas sangat terganggu. Sehingga lalu lintas bisnis pun banyak yang terhambat. Belum lagi ancaman wabah penyakit akibat bencana banjir tersebut.

Melihat fakta-fakta tersebut, sudah menjadi suatu urgensi bagi penduduk kota Jakarta khususnya untuk lebih menyadari akan pentingnya menjaga kelestarian lingkungan agar terhindar dari bencana, untuk kesejahteraan kehidupan. Jika dilihat dari salah satu faktor penyebab banjir, yaitu terdapatnya sampah yang menyumbat aliran air dalam sistem drainase, sudah sangat jelas bahwa sebenarnya bencana banjir dapat dicegah bila seluruh masyarakat memiliki kesadaran untuk membuang sampah pada tempatnya. Faktor sampah ini disinyalir juga merupakan faktor penyebab terjadinya penyempitan dan pendangkalan sungai, juga perusakan hulu sungai. Belum lagi area-area resapan yang sangat terbatas (10\% dari luas wilayah), seharusnya masih bisa diatasi dengan membuat banyak sumur resapan di setiap rumah. Jika sudah menyinggung hal ini, sudah merupakan kewajiban setiap keluarga untuk membuat sumur resapan di rumahnya. Penggunaan air yang berlebihan juga bisa dikategorikan eksploitasi air tanah yang bisa menyebabkan penurunan permukaan tanah.

Membuang sampah pada tempatnya, hemat menggunakan air, bahkan kemauan untuk membuat sumur resapan tersebut termasuk dalam perilaku ramah lingkungan (environmental behavior atau ada pula yang menyebutnya dengan pro-environmental behavior). Perilaku ramah lingkungan secara umum dapat didefinisikan sebagai perilaku yang secara sadar cenderung untuk menekan serendah mungkin dampak negatif dari tindakan seseorang terhadap alam atau lingkungan yang terbangun secara fisik (Kollmuss \& Agyeman dalam H’Mida, Chavez, \& Guindon). Melihat situasi dan kondisi lingkungan fisik kota Jakarta yang semakin kompleks ini Penulis ingin memulai dengan mencari tahu tingkat kesadaran lingkungan masyarakat kota Jakarta dari perilaku ramah lingkungannya. Menyadari bahwa penyebab bencana banjir pun beraneka ragam dan cukup kompleks sehingga diperlukan ilmu dan pengetahuan tertentu, penelitian ini dimulai dari golongan masyarakat yang berasal dari kalangan intelektual. Mahasiswa, sebagai kalangan intelektual muda, diharapkan dapat mulai menerapkan perilaku ramah lingkungan sebagai pionir dalam pendidikan kesadaran lingkungan.

Berdasarkan paparan tersebut, penelitian ingin mengetahui tingkat kesadaran lingkungan mahasiswa. Dalam hal ini penelitian mengambil responden mahasiswa Binus sebagai salah satu universitas swasta berpopulasi terbesar yang sedang menjalani semester kedua sebagai sampel dilihat dari gambaran perilaku ramah lingkungan. Tujuan penelitian ini ialah untuk melihat gambaran secara umum perilaku ramah lingkungan pada mahasiswa Binus semester dua dilihat dari tingkat kesadaran lingkungan. Sedangkan manfaat penelitian ini adalah untuk mendapatkan informasi awal yang dapat digunakan sebagai dasar penentuan intervensi untuk menguatkan perilaku ramah lingkungan terhadap mahasiswa Binus atau penelitian lebih lanjut. Sebelum memulai penelitian dan pembahasan tentang perilaku ramah lingkungan terkait dengan terjadinya bencana banjir, berikut ini ilustrasi proses terjadinya banjir. 


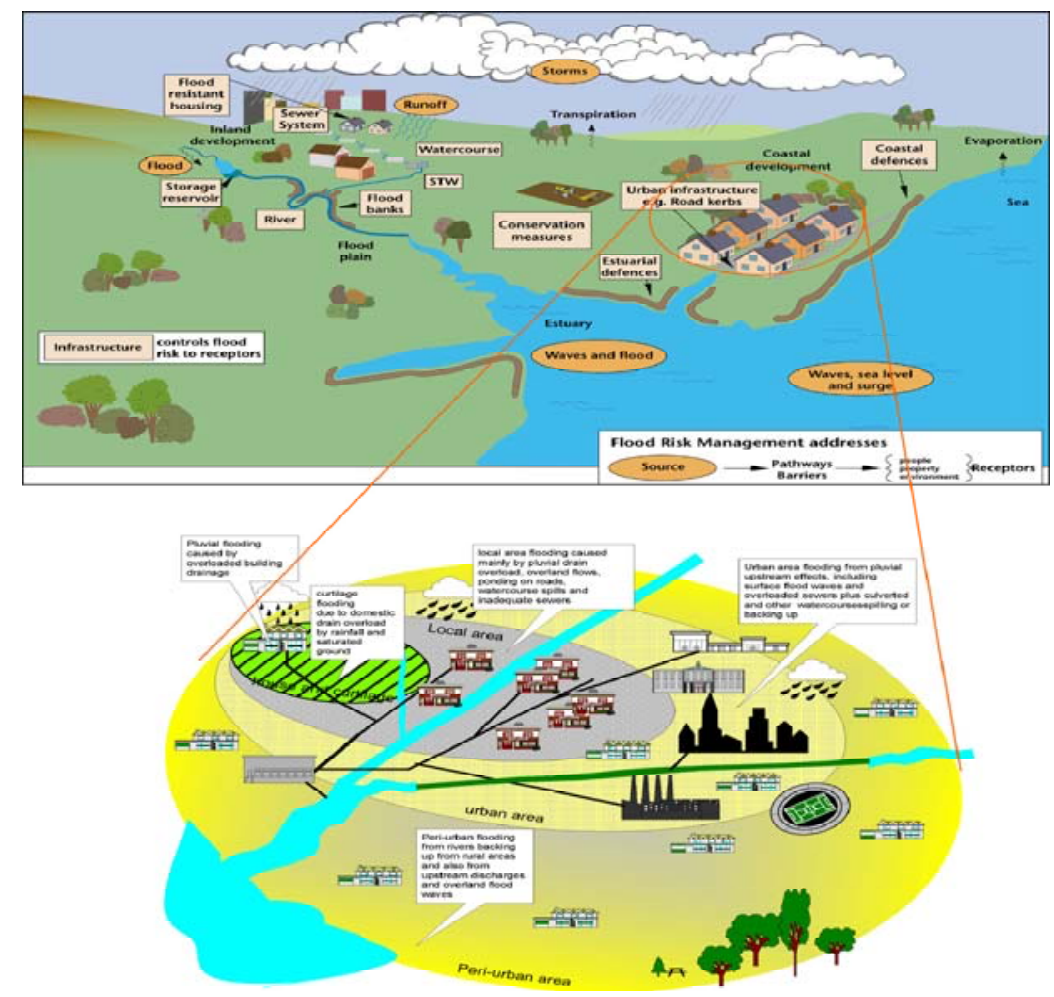

Gambar 1 Proses Terjadinya Banjir di Area Perkotaan (Sumber: Water \& Evans, 2009)

Ilustrasi tersebut jelas mendeskripsikan proses-proses terjadinya banjir. Mulai dari turunnya hujan, hingga air yang gagal terserap tanah ataupun mengalir dalam saluran drainase karena berbagai faktor yang telah disebutkan, membuat genangan-genangan air pada permukaan tanah yang jika tetap dibiarkan, genangan-genangan tersebut akan meninggi dan menyebar luas.

Sikap lingkungan diakui sebagai indikator dan komponen perilaku lingkungan. Ada banyak teori dan pendekatan secara empiris yang meneliti sikap terhadap lingkungan dalam literatur-literatur yang diakui (Tarrant, et.al dalam Kalantari \& Asadi, 2010). Sebagian besar penelitian yang berhubungan dengan masalah ini telah dilakukan sejak 1970 dan seterusnya ketika konseptualisasi sikap lingkungan sebagai konsep penelitian ilmiah mendapatkan perhatian yang lebih dari para peneliti (Dunlap, et.al dalam Kalantari \& Asadi, 2010). Dimensionalitas adalah salah satu faktor yang paling penting dari studi-studi mengenai sikap terhadap lingkungan. Penelitian-penelitian pendahuluan melihat sikap terhadap lingkungan sebagai konsep yang unidimensional. Beberapa waktu kemudian, banyak studi yang mengeksplorasi sifat multidimensi dari sikap terhadap lingkungan. Albrecht, et.al dalam Kalantari \& Asadi (2010) menggunakan analisis faktor dan menemukan tiga dimensi, yaitu keseimbangan alam, pembatasan pertumbuhan, dan manusia terhadap alam. Cluck, et.al dalam Kalantari \& Asadi (2010) mengambil data nasional Amerika Serikat dan mengonseptualisasikan sikap terhadap lingkungan menjadi tiga dimensi konsep, yaitu pandangan umum terhadap lingkungan, kepedulian/perhatian terhadap lingkungan, dan komitmen terhadap lingkungan (Vogel dalam Kalantari \& Asadi, 2010).

Telah banyak literatur yang membahas tentang masalah ini mengindikasikan bahwa yang paling mendekati dalam identifikasi sikap terhadap lingkungan dan perilaku ramah lingkungan sebagai fenomena yang multidimensi (Tuna dalam Kalantari \& Asadi, 2010). Studi ini mengungkapkan beberapa faktor yang secara konsisten berkaitan dengan perilaku ramah lingkungan dari waktu ke waktu dan di seluruh studi yang telah dilakukan. Beberapa studi telah menunjukkan bahwa kerangka hierarki kognitif terdiri dari nilai-nilai dasar, keyakinan-keyakinan umum, sikap-sikap 
tertentu, dan perilaku memberikan dasar yang tepat untuk memahami "environmentalisme". Pada gilirannya, keyakinan umum mempengaruhi sikap yang spesifik juga tindakan ataupun perilaku (Schultz \& Zelezny; Gärling, et.al dalam Kalantari \& Asadi, 2010). Meskipun pengaruh pengetahuan belum diketahui secara ilmiah, ada beberapa studi menunjukkan bahwa pengetahuan memainkan peran penting dalam meningkatkan kualitas sikap terhadap lingkungan dan hubungannya terhadap perilaku dengan memberikan individu kemampuan untuk dapat lebih merumuskan pandangan-pandangan alternatif dan menghadirkan argumen untuk mendukung keyakinan dan perilaku mereka (Mc Farlane \& Boxall dalam Kalantari \& Asadi, 2010).

\section{METODE PENELITIAN}

Penelitian ini dilakukan dengan melakukan survei secara sederhana. Survei dilakukan dengan menyebar kuesioner tentang kesadaran lingkungan dari perilaku keseharian responden, dengan memerhatikan 10 tindakan sederhana (Tabel 2). Responden yang dipilih untuk penelitian ini adalah mahasiswa Binus kelas CB-Spiritual Development semester 2. Faktor-faktor pertimbangan pemilihan ini adalah mengingat salah satu program Binus adalah mencanangkan pendidikan kepedulian terhadap lingkungan melalui beberapa programnya yang salah satunya adalah program Teach for Indonesia (TFI), usia mahasiswa semester 2 yang relatif muda (17-19 tahun) sehingga lebih mudah untuk diberikan intervensi, kelas mata kuliah CB-Spiritual Development yang heterogen pada jurusan mahasiswanya, dan sesuai dengan salah satu topik perkuliahan CB-Spiritual Development yang membahas tentang kepedulian terhadap lingkungan sebagai salah satu indikator kecerdasan spiritual.

Hasil survei diolah dengan menggunakan metode perhitungan statistik dan hasilnya akan ditampilkan dalam bentuk persentase dengan menggunakan tabel dan grafik, karena hasilnya hanya untuk mendapatkan gambaran umum untuk dijadikan informasi dasar yang masih dapat dikembangkan. Kuesioner yang akan digunakan dapat dilihat pada tabel berikut.

Tabel 2 Kuesioner Perilaku Ramah Lingkungan

\begin{tabular}{|c|c|c|c|c|c|c|}
\hline No. & Pernyataan & $\begin{array}{l}\text { Selalu } \\
\text { (5) } \\
\end{array}$ & $\begin{array}{c}\text { Sering } \\
(4) \\
\end{array}$ & $\begin{array}{c}\text { Kadang- } \\
\text { kadang } \\
\text { (3) }\end{array}$ & $\begin{array}{c}\text { Hampir } \\
\text { tidak } \\
\text { pernah } \\
(2) \\
\end{array}$ & $\begin{array}{c}\text { Tidak } \\
\text { Pernah } \\
(1) \\
\end{array}$ \\
\hline 1 & $\begin{array}{l}\text { Saya meletakkan sampah rumah saya di luar sesuai } \\
\text { dengan jadwal kedatangan tukang sampah. }\end{array}$ & & & & & \\
\hline 2 & $\begin{array}{l}\text { Saya menggunakan kembali kantong plastik dari } \\
\text { supermarket. }\end{array}$ & & & & & \\
\hline 3 & $\begin{array}{l}\text { Saya jarang menggunakan kendaraan bermotor } \\
\text { karena melihat udara kota Jakarta sudah terpolusi. }\end{array}$ & & & & & \\
\hline 4 & $\begin{array}{l}\text { Saat menggosok gigi, saya tidak membiarkan keran } \\
\text { air terbuka. }\end{array}$ & & & & & \\
\hline 5 & $\begin{array}{l}\text { Saya menyetir dengan cara yang menghemat bahan } \\
\text { bakar kendaraan saya. }\end{array}$ & & & & & \\
\hline 6 & $\begin{array}{l}\text { Saya membeli susu dan minuman bersoda dalam } \\
\text { kemasan yang bisa dikembalikan (kemasan botol). }\end{array}$ & & & & & \\
\hline 7 & $\begin{array}{l}\text { Saya patuh pada batasan kecepatan mobil yang } \\
\text { berlaku di jalan tol. }\end{array}$ & & & & & \\
\hline 8 & Saya memisahkan sampah botol dari sampah basah. & & & & & \\
\hline 9 & $\begin{array}{l}\text { Setelah piknik, saya meninggalkan taman dalam } \\
\text { keadaan seperti sebelumnya. }\end{array}$ & & & & & \\
\hline 10 & $\begin{array}{l}\text { Saya banyak membicarakan masalah lingkungan } \\
\text { dengan teman-teman saya. }\end{array}$ & & & & & \\
\hline
\end{tabular}

(Sumber: Kalantari \& Asadi, 2010) 
Dilihat dari kuesioner, perilaku ramah lingkungan diukur menggunakan skala Likert dengan 2 variabel, yaitu sikap ramah lingkungan yang terkandung dalam sikap kesadaran lingkungan (environmental awareness) dan frekuensi berperilaku environmental awareness tersebut. Sikap sadar lingkungan tersebut dijabarkan dalam 10 indikator, dan frekuensinya dibagi lagi menjadi 5, yaitu selalu, sering, kadang-kadang, hampir tidak pernah, dan tidak pernah. Lima frekuensi ini langsung diterjemahkan dalam angka dalam skala Likert, yaitu selalu (5), sering (4), kadang-kadang (3), hampir tidak pernah (2), dan tidak pernah (1). Setelah diketahui hasil kuesioner dari tiap responden baru diolah dengan menggunakan SPSS.

\section{HASIL DAN PEMBAHASAN}

Setelah dilakukan penyebaran kuesioner, terkumpul sebanyak 90 responden yang berasal dari dua kelas CB-Spiritual Development. Hasil pengisian kuesioner tersebut dapat dilihat pada tabel berikut.

Tabel 3 Hasil Pengisian Kuesioner

\begin{tabular}{cccccccccccc}
\hline Subject & B1 & B2 & B3 & B4 & B5 & B6 & B7 & B8 & B9 & B10 & Total \\
\hline 1 & 1 & 5 & 2 & 3 & 2 & 3 & 5 & 3 & 5 & 2 & 31 \\
2 & 2 & 3 & 2 & 4 & 4 & 3 & 4 & 2 & 3 & 4 & 31 \\
3 & 3 & 4 & 4 & 5 & 5 & 3 & 3 & 4 & 4 & 5 & 40 \\
4 & 5 & 3 & 3 & 3 & 5 & 1 & 5 & 3 & 1 & 1 & 30 \\
5 & 2 & 4 & 2 & 5 & 1 & 4 & 5 & 4 & 5 & 4 & 36 \\
6 & 5 & 4 & 3 & 5 & 4 & 3 & 3 & 3 & 4 & 3 & 37 \\
7 & 2 & 3 & 2 & 5 & 2 & 4 & 3 & 2 & 2 & 2 & 27 \\
8 & 3 & 3 & 2 & 4 & 4 & 3 & 3 & 3 & 3 & 3 & 31 \\
9 & 3 & 5 & 5 & 5 & 5 & 1 & 5 & 3 & 5 & 3 & 40 \\
10 & 5 & 5 & 1 & 3 & 1 & 4 & 4 & 1 & 5 & 3 & 32 \\
11 & 3 & 5 & 2 & 5 & 3 & 5 & 3 & 3 & 3 & 3 & 35 \\
12 & 5 & 5 & 5 & 3 & 5 & 4 & 3 & 3 & 5 & 3 & 41 \\
13 & 3 & 5 & 5 & 3 & 5 & 5 & 5 & 3 & 5 & 3 & 42 \\
14 & 3 & 5 & 1 & 3 & 1 & 5 & 5 & 1 & 5 & 4 & 33 \\
15 & 1 & 3 & 2 & 3 & 1 & 2 & 4 & 2 & 4 & 3 & 25 \\
16 & 5 & 5 & 3 & 4 & 3 & 4 & 3 & 2 & 4 & 3 & 36 \\
17 & 2 & 4 & 1 & 4 & 3 & 3 & 3 & 2 & 4 & 2 & 28 \\
18 & 3 & 5 & 2 & 4 & 5 & 3 & 4 & 3 & 4 & 3 & 36 \\
19 & 1 & 5 & 4 & 1 & 4 & 3 & 2 & 1 & 5 & 2 & 28 \\
20 & 5 & 3 & 3 & 2 & 4 & 3 & 4 & 2 & 4 & 3 & 33 \\
21 & 3 & 5 & 3 & 5 & 3 & 4 & 3 & 2 & 5 & 3 & 36 \\
22 & 4 & 4 & 4 & 3 & 3 & 3 & 3 & 3 & 4 & 3 & 34 \\
23 & 1 & 4 & 1 & 4 & 3 & 3 & 3 & 3 & 5 & 3 & 30 \\
24 & 5 & 5 & 3 & 3 & 3 & 2 & 4 & 1 & 4 & 3 & 33 \\
25 & 4 & 5 & 3 & 4 & 3 & 2 & 3 & 4 & 5 & 3 & 36 \\
26 & 3 & 5 & 1 & 3 & 2 & 3 & 3 & 1 & 2 & 2 & 25 \\
27 & 3 & 3 & 3 & 4 & 3 & 3 & 3 & 5 & 3 & 3 & 33 \\
\hline & & & & & & & & & & & \\
& 5 & 5 & 53
\end{tabular}




\begin{tabular}{|c|c|c|c|c|c|c|c|c|c|c|c|}
\hline 28 & 5 & 3 & 3 & 1 & 3 & 2 & 3 & 2 & 3 & 3 & 28 \\
\hline 29 & 3 & 3 & 2 & 5 & 4 & 5 & 4 & 4 & 1 & 3 & 34 \\
\hline 30 & 4 & 4 & 3 & 5 & 4 & 3 & 3 & 4 & 4 & 3 & 37 \\
\hline 31 & 5 & 5 & 3 & 5 & 5 & 3 & 3 & 3 & 4 & 4 & 40 \\
\hline 32 & 4 & 4 & 1 & 5 & 4 & 4 & 3 & 3 & 4 & 4 & 36 \\
\hline 33 & 4 & 5 & 2 & 3 & 3 & 3 & 4 & 3 & 3 & 3 & 33 \\
\hline 34 & 3 & 3 & 2 & 5 & 5 & 4 & 4 & 3 & 5 & 2 & 36 \\
\hline 35 & 1 & 5 & 5 & 3 & 4 & 4 & 5 & 2 & 4 & 4 & 37 \\
\hline 36 & 2 & 4 & 3 & 3 & 3 & 3 & 3 & 3 & 3 & 3 & 30 \\
\hline 37 & 5 & 4 & 2 & 4 & 5 & 2 & 4 & 5 & 4 & 4 & 39 \\
\hline 38 & 4 & 4 & 4 & 3 & 3 & 3 & 4 & 4 & 4 & 4 & 37 \\
\hline 39 & 5 & 5 & 1 & 2 & 4 & 3 & 2 & 3 & 3 & 3 & 31 \\
\hline 40 & 3 & 5 & 3 & 3 & 3 & 3 & 3 & 3 & 3 & 3 & 32 \\
\hline 41 & 3 & 5 & 3 & 3 & 2 & 2 & 5 & 2 & 3 & 2 & 30 \\
\hline 42 & 0 & 5 & 5 & 3 & 5 & 5 & 5 & 3 & 5 & 3 & 39 \\
\hline 43 & 5 & 5 & 2 & 3 & 3 & 3 & 4 & 3 & 4 & 3 & 35 \\
\hline 44 & 4 & 5 & 4 & 5 & 4 & 3 & 3 & 3 & 4 & 4 & 39 \\
\hline 45 & 3 & 4 & 3 & 4 & 4 & 3 & 4 & 3 & 4 & 4 & 36 \\
\hline 46 & 5 & 4 & 3 & 5 & 1 & 3 & 1 & 3 & 2 & 3 & 30 \\
\hline 47 & 5 & 5 & 3 & 5 & 5 & 4 & 1 & 1 & 5 & 3 & 37 \\
\hline 48 & 4 & 5 & 5 & 4 & 4 & 2 & 3 & 2 & 3 & 1 & 33 \\
\hline 49 & 4 & 5 & 3 & 3 & 3 & 2 & 5 & 1 & 5 & 3 & 34 \\
\hline 50 & 5 & 5 & 3 & 4 & 5 & 3 & 5 & 2 & 4 & 1 & 37 \\
\hline 51 & 4 & 5 & 5 & 3 & 3 & 3 & 3 & 2 & 4 & 3 & 35 \\
\hline 52 & 4 & 4 & 3 & 5 & 5 & 3 & 4 & 3 & 4 & 4 & 39 \\
\hline 53 & 5 & 5 & 2 & 3 & 4 & 3 & 3 & 2 & 3 & 5 & 35 \\
\hline 54 & 5 & 4 & 4 & 3 & 4 & 1 & 4 & 4 & 4 & 3 & 36 \\
\hline 55 & 2 & 5 & 3 & 5 & 3 & 4 & 5 & 5 & 5 & 3 & 40 \\
\hline 56 & 2 & 3 & 2 & 5 & 4 & 3 & 5 & 3 & 3 & 3 & 33 \\
\hline 57 & 3 & 3 & 4 & 5 & 3 & 2 & 5 & 3 & 5 & 3 & 36 \\
\hline 58 & 5 & 5 & 3 & 3 & 3 & 3 & 3 & 2 & 2 & 3 & 32 \\
\hline 59 & 4 & 3 & 1 & 5 & 5 & 3 & 1 & 5 & 5 & 5 & 37 \\
\hline 60 & 4 & 5 & 2 & 5 & 4 & 3 & 4 & 3 & 4 & 3 & 37 \\
\hline 61 & 4 & 5 & 3 & 5 & 4 & 5 & 4 & 3 & 4 & 4 & 41 \\
\hline 62 & 3 & 4 & 2 & 5 & 2 & 3 & 5 & 4 & 4 & 3 & 35 \\
\hline 63 & 3 & 4 & 1 & 1 & 3 & 3 & 3 & 1 & 5 & 3 & 27 \\
\hline 64 & 5 & 5 & 2 & 4 & 3 & 3 & 3 & 2 & 2 & 3 & 32 \\
\hline 65 & 3 & 4 & 3 & 5 & 4 & 4 & 4 & 3 & 4 & 3 & 37 \\
\hline 66 & 4 & 5 & 1 & 5 & 4 & 3 & 5 & 1 & 1 & 3 & 32 \\
\hline 67 & 3 & 4 & 2 & 5 & 4 & 3 & 4 & 2 & 4 & 2 & 33 \\
\hline 68 & 5 & 5 & 2 & 5 & 5 & 2 & 5 & 5 & 3 & 1 & 38 \\
\hline 69 & 5 & 5 & 5 & 3 & 1 & 3 & 5 & 2 & 1 & 2 & 32 \\
\hline 70 & 1 & 3 & 3 & 5 & 3 & 3 & 3 & 2 & 1 & 1 & 25 \\
\hline 71 & 3 & 5 & 3 & 5 & 4 & 3 & 4 & 4 & 3 & 2 & 36 \\
\hline
\end{tabular}




\begin{tabular}{llllllllllll}
\hline 72 & 4 & 5 & 1 & 5 & 3 & 5 & 4 & 1 & 5 & 2 & 35 \\
73 & 2 & 4 & 2 & 5 & 3 & 3 & 4 & 3 & 3 & 1 & 30 \\
74 & 5 & 5 & 3 & 4 & 4 & 2 & 5 & 5 & 3 & 3 & 39 \\
75 & 3 & 4 & 4 & 4 & 3 & 3 & 3 & 3 & 4 & 2 & 33 \\
76 & 1 & 4 & 1 & 2 & 4 & 2 & 5 & 3 & 4 & 2 & 28 \\
77 & 1 & 5 & 1 & 2 & 4 & 1 & 5 & 3 & 5 & 2 & 29 \\
78 & 3 & 5 & 2 & 1 & 3 & 3 & 1 & 2 & 3 & 3 & 26 \\
79 & 4 & 4 & 2 & 3 & 4 & 3 & 4 & 4 & 4 & 3 & 35 \\
80 & 3 & 5 & 5 & 5 & 5 & 3 & 5 & 2 & 5 & 3 & 41 \\
81 & 4 & 5 & 3 & 2 & 4 & 4 & 2 & 3 & 3 & 2 & 32 \\
82 & 1 & 4 & 1 & 5 & 3 & 2 & 3 & 3 & 5 & 2 & 29 \\
83 & 4 & 5 & 5 & 5 & 5 & 3 & 3 & 4 & 3 & 3 & 40 \\
84 & 5 & 5 & 2 & 1 & 3 & 4 & 3 & 1 & 3 & 2 & 29 \\
85 & 1 & 5 & 1 & 5 & 5 & 1 & 5 & 2 & 5 & 3 & 33 \\
86 & 5 & 3 & 4 & 2 & 5 & 2 & 3 & 3 & 3 & 3 & 33 \\
87 & 3 & 5 & 2 & 3 & 3 & 3 & 3 & 1 & 5 & 1 & 29 \\
88 & 1 & 5 & 3 & 5 & 2 & 1 & 5 & 3 & 4 & 3 & 32 \\
89 & 4 & 5 & 3 & 2 & 3 & 3 & 3 & 3 & 2 & 3 & 31 \\
90 & 5 & 5 & 2 & 4 & 4 & 3 & 3 & 5 & 4 & 4 & 39 \\
\hline
\end{tabular}

B1sampai dengan B10 mendeskripsikan butir pertanyaan yang terdiri dari 10 aspek perilaku ramah lingkungan. Sedangkan angka 1 sampai dengan 5 yang terdapat di dalam tabel mendeskripsikan frekuensi perilaku ramah lingkungan tersebut dilaksanakan. Jika diperhatikan nilai totalnya, didapatkan 18 varian nilai yang mencerminkan variasi tingkat kesadaran terhadap lingkungan (environmental awareness). Kedelapan belas nilai tersebut adalah 25 sampai dengan 42. Hasil kuesioner tersebut setelah diolah dengan menggunakan SPSS didapat hasil sebagai berikut.

Tabel 4 Hasil Pengolahan Data

\begin{tabular}{rrrrrr}
\hline & Frequency & Percent & Valid Percent & $\begin{array}{c}\text { Cumulative } \\
\text { Percent }\end{array}$ \\
\hline Valid & 25 & 3 & 3.3 & 3.3 & 3.3 \\
& 26 & 1 & 1.1 & 1.1 & 4.4 \\
& 2 & 2.2 & 2.2 & 6.7 \\
28 & 4 & 4.4 & 4.4 & 11.1 \\
29 & 4 & 4.4 & 4.4 & 15.6 \\
30 & 6 & 6.7 & 6.7 & 22.2 \\
31 & 5 & 5.6 & 5.6 & 27.8 \\
32 & 8 & 8.9 & 8.9 & 36.7 \\
33 & 11 & 12.2 & 12.2 & 48.9 \\
34 & 3 & 3.3 & 3.3 & 52.2 \\
35 & 7 & 7.8 & 7.8 & 60.0 \\
36 & 11 & 12.2 & 12.2 & 72.2 \\
37 & 9 & 10.0 & 10.0 & 82.2 \\
38 & 1 & 1.1 & 1.1 & 83.3 \\
39 & 6 & 6.7 & 6.7 & 90.0 \\
40 & 5 & 5.6 & 5.6 & 95.6 \\
41 & 3 & 3.3 & 3.3 & 98.9 \\
42 & 1 & 1.1 & 1.1 & 100.0 \\
Total & 90 & 100.0 & 100.0 & \\
\hline
\end{tabular}


Delapan belas varian nilai tersebut dapat dilihat pada grafik berikut.

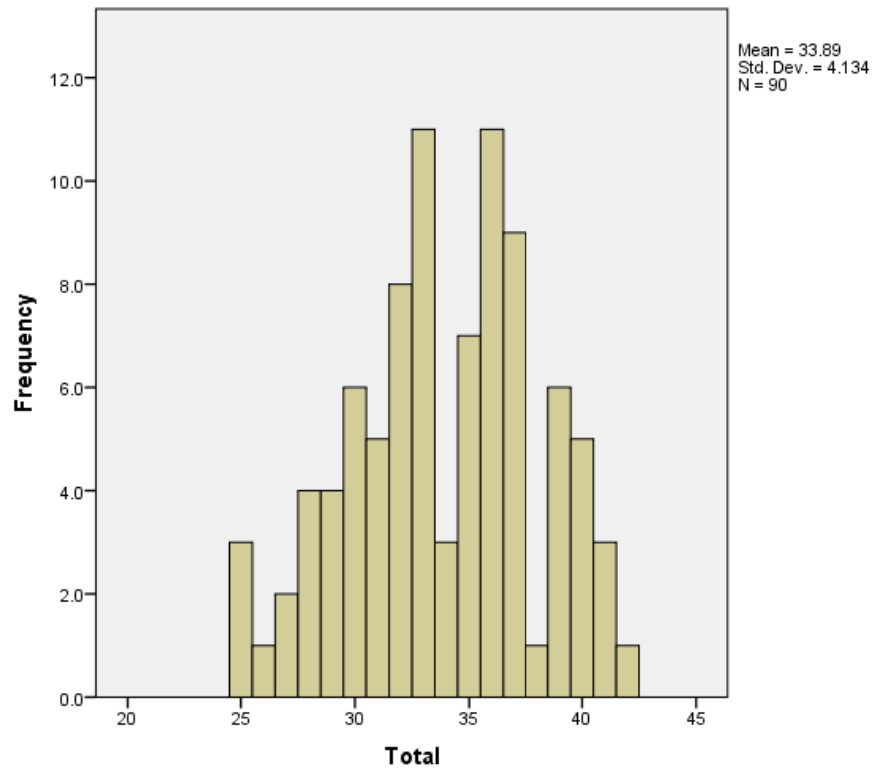

Gambar 2 Grafik Penyebaran Varian Perhitungan Total Frekuensi Pelaksanaan Perilaku Ramah Lingkungan

Jika dilihat dari grafik tersebut, rata-rata total frekuensi tertinggi dari pelaksanaan perilaku ramah lingkungan adalah 33 dan 36, sedangkan yang terendah adalah 26 dan 42. Makin tinggi nilai total, makin sering responden melakukan tindakan yang mencerminkan environmental awareness. Dengan demikian diasumsikan makin ramah lingkungan perilakunya, begitu pula sebaliknya. Jika dibagi menjadi 3 bagian, didapat sebagai berikut. Bagian I (6 nilai total terendah), yaitu 25-30 total frekuensinya adalah 20 (20 responden). Bagian II (6 nilai total pertengahan), yaitu 31-36, total frekuensinya adalah 45 (45 responden). Bagian III (6 nilai total tertinggi), yaitu 37-42, total frekuensinya adalah 25 (25 responden). Total responden adalah 90 responden.

\section{SIMPULAN}

Merujuk pada hasil perhitungan yang ada dengan menggunakan metode statistik dan SPSS, dapat disimpulkan bahwa mahasiswa Binus semester 2 kelas mata kuliah CB-Spiritual Development masih berbentuk grafik distribusi normal. Dilihat dari frekuensi nilai total, yang merujuk pada jumlah responden, dapat disimpulkan bahwa mahasiswa yang tergolong rendah kesadaran lingkungannya adalah sebesar 22,22\%; mahasiswa yang sedang kesadaran lingkungannya adalah sebesar 50\%; dan mahasiswa yang tinggi kesadaran lingkungannya adalah sebesar 27,78\%. Tingkat kesadaran lingkungan ini dianggap mencerminkan perilaku ramah lingkungan mahasiswa. Jika digambarkan dengan diagram pie adalah sebagai berikut. 


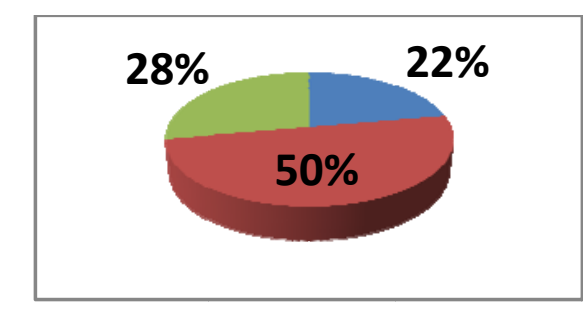

Gambar 3 Persentase Klasifikasi Mahasiswa

Menurut Tingkat Kesadaran Lingkungan

Diharapkan dengan gambaran demikian, mahasiswa Binus sebagai bagian dari kalangan masyarakat intelektual muda Jakarta, dapat lebih mudah dididik agar memiliki kesadaran lingkungan yang tinggi dan berperilaku lebih ramah lingkungan. Dengan terdidiknya mahasiswa Binus untuk berperilaku ramah lingkungan, diharapkan Binus dapat memberi kontribusi yang lebih kepada kota Jakarta untuk meningkatkan kualitas dan menjaga kelestarian lingkungan kota Jakarta.

\section{DAFTAR PUSTAKA}

Bappenas. (2007). Penjelasan Menteri Negara PPN/Kepala Bappenas tentang Hasil Penilaian Kerusakan dan Kerugian Pascabencana Banjir Awal Februari di Wilayah Jabodetabek (Jakarta, Bogor, Depok, Tangerang dan Bekasi). Jakarta: Kementerian Negara Perencanaan Pembangunan Nasional, Republik Indonesia.

DetikNews. (2013). Diakses dari news.detik.com edisi Selasa, 22 Januari 2013.

H’Mida, S., Chavez, E., \& Guindon, C. (2008). Determinants of Pro-Environmental Behaviours Within Individual Consumers. Journal of Economic Literature (JEL) Classification, M31. pp. 1-12 Diakses 30 September 2013 dari http://www.up.edu.mx/files_uploads/15025_turkey.pdf

Kalantari \& Asadi. (2010). Designing a Structural Model for Explaining Environmental Attitude and Behavior of Urban Residents (Case of Tehran). Scientific Journal. Karaj: University of Tehran.

Tempo. (2013). Diakses dari Tempo.co edisi 26 Februari 2013. University (Elsevier Journal)

Water and Evans. (2009). Land Use, Water Management, and Future Flood Risk. London: Oxford.

Wikipedia. (6 Juni 2013). Banjir Jakarta 2013. Diakses 30 September 2013 dari http://id.wikipedia.org/wiki/Banjir_Jakarta_2013. 